\title{
The public as a limit to technology transfer: The influence of knowledge and beliefs in attitudes towards biotechnology in the UK
}

\author{
Joan Costa-Font $\cdot$ Elias Mossialos
}

(C) Springer Science+Business Media, LLC 2006

\section{Erratum to: J Technol Transfer DOI: 10.1007/s10961-006-0019-3}

The publisher apologizes for the error in this article that appeared in volume 31, number 6. Author Joan Costa-Font should have been listed with two affiliations (London and Spain) and Elias Mossialos should have one affiliation in London.

The online version of the original article can be found at http://dx.doi.org/10.1007/s10961-006-0019-3

J. Costa-Font $(\bowtie) \cdot$ E. Mossialos

LSE Health and Social Care, Cowdray House, Houghton Street, London WC2A 2AE, UK e-mail: J.Costa-Font@Ise.ac.uk

E. Mossialos

e-mail: E.A.Mossialos@Ise.ac.uk

J. Costa-Font

Departament de Teoria Economica, Unniversitat de Barcelona, Barcelona, Spain 